\title{
IS THERE A DIFFERENCE BETWEEN THE METAPHYSICS OF A- AND B-TIME?
}

\author{
L. NATHAN OAKLANDER \\ UNIVERSITY OF MICHIGAN-FLINT
}

\begin{abstract}
Clifford Williams has recently argued that the dispute between $\mathrm{A}$ - and B-theories, or tensed and tenseless theories of time, is spurious because once the confusions between the two theories are cleared away there is no real metaphysical difference between them. The purpose of this paper is to dispute Williams's thesis. $I$ argue that there are important metaphysical differences between the two theories and that, moreover, some of the claims that Williams makes in his article suggest that he is sympathetic with a B-theoretic ontology.
\end{abstract}

\section{I}

n a recent and provocative paper, "The Metaphysics of A- and B-Time," Clifford Williams (1996b) has posed a challenge to those who hold either an A-theory or a B-theory of time. The challenge is to explain just how these two theories differ, for, according to Williams, once the misinterpretations of the theories are cleared away there is no longer any coherent way of stating what differentiates them. Although there is much that is valuable in Williams's indistinguishability argument, he is mistaken when he claims that the traditional issue between A- and B-theories is a pseudo problem. What I think he should have claimed, and to some extent has shown, is that there really is only one kind of time, namely B-time, since when the B-theory is correctly understood, it will be seen to be adequate to our experience of the passage of time, self-consistent, and true.

Clearly, any full defense of B-time lies outside of the scope of this paper. ${ }^{1}$ My aims, therefore, are much more limited. I shall attempt to show, contrary to Williams's main thesis, that there is, or rather are, coherent ways of stating what differentiates the two theories. I shall proceed by first pointing out a strong prima facie ground for believing that a distinction between the two 
theories exists. Then, after discussing Williams's reasons for claiming that there is no difference between A- and B-time, I shall explain what I take the differences between the two theories to be. Finally, I shall briefly consider reasons for suggesting that Williams's views are supportive of the B-theory.

My first argument against Williams is that if we accept his thesis that Aand $\mathrm{B}$-theories are indistinguishable, then seemingly absurd consequences follow. To see why, note that Williams treats A-theorists as a relatively monolithic group, even though there are a variety of different versions of A-time. Traditionally, defenders of A-time have maintained that in addition to temporal (B-) relations of earlier, later, and simultaneity, events exemplify the monadic temporal (A-) properties of pastness, presentness, and futurity (see Gale, 1968, and Smith, 1993). There are other tensers who accept A-properties as primitive, but maintain that $\mathrm{B}$-relations are elimininable from an adequate ontology of time since they can be analyzed in terms of A-properties and the passage of time. I interpret McTaggart's (1908) positive theory of time to be of this ilk. ${ }^{2}$ Still other defenders of the A-theory reject tensed properties and temporal relations and countenance only (present) tensed facts (Prior, 1968).

Further variations of the A-theory emerge when its proponents attempt to avoid McTaggart's paradox. Thus John Bigelow (1991) has recently attempted to avoid McTaggart's apparent inconsistency in attributing to an event incompatible A-properties by relativizing tensed properties not to times, but to possible worlds. At one point in his musings about time, George Schlesinger (1980) sought to avoid McTaggart's conundrum by appealing to a second time dimension; and Smith's (1993) way out implies an allegedly nonvicious infinite regress of presentness inhering in its own inherences. There are other versions of the A-theory, some of which reject the moving NOW, as well as both tensed properties and Prior-type theories (see Zeilicovici, 1994; Tooley, 1997; and Lowe, 1998).

On the face of it, therefore, we have a variety of different versions of temporal passage. But if Williams's thesis were correct, and A-time is indistinguishable from B-time, then all of these different versions of A-time would be metaphysically indistinguishable from B-time, and so metaphysically indistinguishable from each other. Since these consequences are absurd, we can infer that Williams's main thesis, from which they follow, is mistaken.

Having made this argument, I must confess that I do not regard it as constituting a decisive objection to Williams's thesis. For in reply, Williams might very well claim that he regards my seemingly absurd consequence (that the different A-theories are indistinct) more as a statement of his thesis than as an objection to it. Thus more needs to be done to undermine Williams's position. Specifically, I must explain what are the metaphysical differences between the two positions. I think the best way to do that is by asking why Williams thinks that there are no metaphysical differences between A- and B-time.

Williams argues that there are two ambiguities in the way in which the debate between the A- and B-theories has usually been couched, and once 
these ambiguities are cleared away only one conception of time will remain. First, it is claimed that whereas a defender of A-time believes in objective temporal passage, or temporal becoming, defenders of B-time deny it. However, Williams argues that this way of understanding the dispute is ambiguous and leads to a misconstrual of B-time. A-theorists take the B-theorist denial of passage to be tantamount to a denial that "time contains any transition or succession or 'movement' from time to time" (372). Thus A-theorists who believe that time contains succession reject the B-theory. To interpret the B-theorist denial of passage in this way is, according to Williams, to fall prey to the misinterpretation of the B-series as a simultaneous whole, or totem simul, in which all of the parts of a four-dimensional space-time exist at once. On the other hand, if B-time does contain succession or 'movement' from time to time, then the question arises "how can we differentiate it from passage in A-time?" (372).

Williams is correct in saying that it is a misinterpretation to claim that the terms of the B-series exist all at once. Where he goes wrong, and thereby perpetuates his own belief that there is no difference between A- and B-time, is in maintaining that in order for there to be time there must be "passage," "transition," or "movement from time to time." For here he is assuming that the preanalytic language we use to talk about time and the beliefs we have about time, are tantamount to a metaphysical analysis of time itself. In order to talk and communicate about time there must be tensed expressions that reflect time's passing, but, according to the B-theorist, it does not follow that the correct ontology of time must contain transition, temporal passage, or flow. ${ }^{3}$ The rock-bottom feature of time that must be accepted on all sides is that there is change, and the different views concerning the nature of change constitute the difference between A- and B-theories of time. To assert that for time to be real there must be succession (i.e., temporal relations) or (as if they are equivalent) movement or transition from time to time, already assumes that there is no difference between A- and B-time. For, as we shall see below, on some versions of the metaphysics of A-time (for example, presentism) temporal relations do not exist, and on all versions of the metaphysics of Btheory there is no movement, transition, or temporal passage understood as something beyond that to be found in B-relations.

A-theorists' misunderstanding of the B-theory is further suggested by the second way of drawing the distinction between the two theories. It is often claimed that whereas A-time holds that only the present exists or is real, in Btime all events are ontologically on a par, being equally real. Williams says that this way of drawing the distinction is ambiguous since it suggests that the B-theory must deny that events cease to exist or come into existence, and so deny that there is any transition in time. Once again, he says that to misconstrue B-time in this way is to attribute to the B-theory the view that "all of time exists 'simultaneously' as a sort of four-dimensional solid in the spacetime continuum" (373). ${ }^{4}$ However, once these ways of distinguishing the two 
theories are separated from their misconstruals, the difference between A- and B-time must be that there are two different kinds of transition: A-transition and B-transition. In that case, Williams says that "it is no longer apparent how the two theories differ" (375).

It appears, however, that once again it is Williams who has confused our ordinary way of speaking about time with the various metaphysical analyses that are claimed to underlie them. We may admit, as assuredly is the case, that all events in B-time do not exist simultaneously. But it does not follow from that, nor do detensers believe, that in order for there to be time there must be some basic unanalyzable concept of coming into existence and ceasing to exist. On the B-theory, expressions that assert the coming into existence and ceasing to exist of events are eliminable in terms of expressions that state their truth conditions. In short, an ontologically adequate representation of time will not contain expressions that reflect the coming into existence and ceasing to exist of events over and above their tenseless location at different dates. Nevertheless, in ordinary language and thought, sentences that assert that events do not yet exist, or have come into existence or have ceased to exist, are meaningful, necessary for practical purposes, and often true.

According to Williams, not only have A-theorists misunderstood B-time, but B-theorists have misunderstood A-time. The way in which B-theorists have misunderstood A-time is by thinking of temporal passage as something extra, added to, and over and above, succession in B-time. That is, B-theorists have construed the A-theory to be holding that time consists of the property of presentness moving along an ordered B-series of moments or events. Williams claims that this misinterpretation of A-time by B-theorists leads them to reject the A-theory because it renders A-time "incomprehensible," "absurd," and "contradictory because it is the movement of time in time" (376). Williams goes on to claim that although A-theorists "sometimes convey the idea that time consists of some literal unexplainable motion, what they really want to convey is that the passage involved in A-time is different from the transition involved in B-time" (376; emphasis added).

It seems to me, however, that it is Williams who misinterprets the A-theory and reveals his B-theorist bias when he claims that A-theorists do not really want to claim that "presentness is a property of events over and above their occurrence at particular clock times, a property that events gain and lose" (376). There obviously are leading A-theorists who maintain, and argue vigorously for, precisely the view Williams claims is incoherent and unintelligible. Consider, for example, the following passages from Quentin Smith:

[T]ime is neither causation, motion, physicality, mentality, or anything else. Time is time. Time is a series of items related by primitive and irreducible relations of earlier, later and simultaneous and possessing monadic properties of futurity, presentness or pastness). ${ }^{5}$

[T] he tenser acknowledges that events are B-related and that A-sentences imply facts about their B-relations. . . . The thesis the tenser wants to 
establish is that A-sentences also convey information about the Aproperties of events. ([1993], 10)

Ned Markosian also understands the passage of time in a way that no Btheorist would accept. According to Markosian:

$[\mathrm{T}]$ here is a ... process by which times and events successively possess different A-properties. January 1st, 2000 is currently future, but it is becoming less and less remotely future all the time, and there is nothing that anyone can do to halt or even to slow this process. . . In what follows, I will refer to the process by which times and events successively possess different A-properties as the pure passage of time... As I see it, the A-property thesis and the pure passage of time thesis together constitute the metaphysical core of the view that time passes. ([1993], 835, 836; emphasis added)

Since, on Markosian's view, events or moments successively possess different A-properties, the pure passage of time involves something more than the time relations found in B-time. Thus the notion that time consists of both temporal relations and transitory temporal properties is a theory that many Atheorists really want to maintain, and it reflects a metaphysical difference between what kinds of temporal entities exist in A- and B-time.

Williams shows his B-theory bias by taking for granted that McTaggart, D. C. Williams, Grünbaum, Smart, and others have effectively demonstrated the "myth" of passage as something extra, over and above B-relations (a point I shall return to below). However, since Markosian, Schlesinger (1994), Smith $(1993,1994)$, and other A-theorists have presented arguments that directly respond to the various dialectical challenges to A-time, Williams cannot simply assume that the traditional way of drawing the distinction between A- and B-time is absurd.

Nevertheless, Williams may object that the traditional way of distinguishing A- and B-time does not mark a real metaphysical difference because "it is not evident how the shift of presentness from event to event in A-time differs from the transition from occurrence to occurrence in B-time" (380). By further exploring how A-passage and B-succession might differ, we shall come to understand a further metaphysical difference between the two theories.

We can begin to see how A- and B-time can be distinguished by considering what motivates the two theories, namely, the problem of change. ${ }^{6} \mathrm{Al}-$ though it is debatable whether or not time involves change, it is surely not debatable that change involves time. For if we are to understand how a single thing can have incompatible properties, and thus satisfy one essential ingredient of change, we must in some way specify the different times at which it possesses those properties. For example, if a leaf changes its color from green to brown, it must first be green and then be brown, that is, it must be green at a time earlier than the time it is brown. Thus to explain the reality of change is to explain how a single thing can have incompatible properties successively, 
or one before the other. What, then, is succession and the relations of earlier and later? Alternatively, how can we account for the difference between the temporal change of the color of a leaf, and the spatial "change" of, say, the color of a lawn from being green at one end and brown at the other? By turning to those questions, we shall be able to better understand the metaphysical differences between A-time and B-time. First, however, a brief discussion of relations in general will be useful.

With few exceptions, and until the discussions by Bradley (1897) and Russell (1903) around the turn of the century, relations were not recognized as constituting a category in their own right. Rather, the ontological ground of relations was believed to be in the nonrelational properties of the terms said to be related. ${ }^{7}$ Thus, for example, consider the relational statement that

\section{1. $a$ is $\mathrm{R}$ to $b$}

On the traditional or monadistic account (to use Russell's phrase), $a$ is R to $b$ does not contain the relation $\mathrm{R}$ as a constituent. Rather, the objective facts represented by (1) are nonrelational.

2. $a$ is $r_{1}$ and $b$ is $r_{2}$

On this account of relations, the nonrelational properties, $r_{1}$ and $r_{2}$ are the foundation or ontological ground of the relation. For example, if Socrates is taller than Simmias, then he is so in virtue of the height that Socrates and Simmias each possess. In other words, on the reductionist view, relations do not have ontological status; they do not form a category of their own. For Russell, on the other hand, relations cannot be reduced to monadic properties of their terms. In particular, temporal relations are such that their terms can be related, that is, $a$ can be earlier than $b$, even though neither $a$ nor $b$ exemplify any A-properties.

To connect this brief discussion of relations with the issue at hand, I suggest that a further fundamental difference between A- and B-time is that on the B-theory there are, whereas on some versions of the A-theory there are not, primitive temporal relations. Thus for some B-theorists, including Russell (1915), (the early) C. D. Broad (1912), (the early) C. Williams (1994), Oaklander $(1984,1998)$, and others, temporal relations are external in just this sense: They are primitive and unanalyzable relations indefinable in terms of tensed predicates and irreducible to tensed properties. On this version of B-time, the difference between spatial and temporal relations is an irreducible qualitative difference, and it is a mistake to suppose that if time is the mere succession of events, then the change involved is exactly like the spatial "change" in the color of the lawn one observes as one walks from the front to the back. The relation that distinguishes temporal order is just different from any spatial relation in the same sense that red and green are just different. I should note, however, that some B-theorists do not (and perhaps need not) construe the earlier/later relations as primitive. Detensers such as Grünbaum (1963), 
Mellor (1998), and Le Poidevin (1992), maintain that temporal relations are definable in terms of causal relations, and the direction of time and change is grounded in the direction of causality. For these philosophers, the crucial feature of B-time is not that B-relations are primitive or irreducible, but that they cannot be reduced to A-properties.

For some A-theorists, on the other hand, temporal relations are analyzable in terms of A-properties, and they must be if there is to be genuine succession and temporal change. Thus, for example, McTaggart attempted to define "earlier than" in terms of the notions of "past," present," and "future," and in his other positive reflections on time maintains that the direction of time and change (i.e., B-relations) depend upon the application of the A-series to the ordered, but nontemporal, C-series. ${ }^{8}$ Both of these claims support the idea that he did not countenance primitive temporal relations in his ontology even before he rejected the reality of time.

More recently, John Bigelow has attempted to vindicate McTaggart's positive view by arguing that in order to make sense of the belief that time passes, we must take "as the more primitive notions those of the passage of time, of past, present and future, and not those of earlier and later, before and after. ... And I will try, in fact, to define earlier and later in terms of the passage of time, rather than the other way around" $(1991,3)$. Then, after providing a reductive analysis of the earlier/later relation, Bigelow asserts:

[W]e thus have a way of meeting McTaggart's challenge. We can explain what makes the earlier/later ordering of events a temporal ordering, by showing that it derives from the prior, specifically temporal properties of pastness, presentness and futurity $(1991,13) .^{9}$

Clearly, by "prior" Bigelow does not mean temporally prior, but ontologically prior, and so the primitive temporal existents in his ontology are the intrinsic, nonrelational properties of pastness, presentness, and futurity, which, together with the hypothesis of possible worlds "make the earlier/later relation a temporal one" $(1991,3)$. Thus, contrary to Williams avowals, there is a fundamental difference between A-passage and B-succession and it concerns what categories of temporal entities exist. According to A-time (at least on one version), temporal relations are reducible to temporal properties (and the $\mathrm{C}$-series or possible worlds). According to B-time, on the other hand, there are no nonrelational temporal properties; the only intrinsically temporal entities are relations.

This difference between the A- and B-theories of transition and succession can also be understood by considering yet another version of the A-theory, namely, "presentism." To understand the motivation for presentism and how it is metaphysically distinct from the B-theory, we need to consider an apparent peculiarity of temporal relations. On the one hand, temporal relations, like virtually all relations, involve existents as terms. ${ }^{10}$ In order for a relation to relate there must be relata. Thus if John is taller than Paul, then both John 
and Paul must exist. Of course, there may be relations that relate a thing to itself, such as identity, but even here, in order for the relation of identity to hold between a thing and itself, the entity in question must exist. On the other hand, it appears that in order for the earlier/later relation to obtain, at least one of the terms must either no longer or not yet exist. For example, the 1992 Olympic Games are earlier than my writing this sentence and for that reason have, in some sense, ceased to exist, and the 2000 Olympic Games are later than my writing this sentence and for that reason do not yet exist. Thus the temporal relations of earlier and later both require and forbid existing terms. One way of understanding the problem of time, and the difference between the A- and B-time is by considering how A- and B-theories attempt to deal with this prima facie paradox concerning temporal relations.

On the presentist version of the A-theory, "only the present exists." Thus, in response to the dilemma concerning temporal relations, the presentist maintains events that now exist are not in any way related to earlier or later events, since earlier or later events either no longer or do not yet exist; they are not around to stand in relation to anything. ${ }^{11}$ In other words, presentists avoid paradox by rejecting temporal felations as primitive existents and countenancing only facts about the present.

For the B-theorist, all events exist at the time they do; that is, they are located at the time they are, with the properties that they have, regardless of what time it is. Nevertheless, B-theorists can give an explanation of an event's coming to be and ceasing to be. On their reading, a headache's ceasing to exist over the interval $t_{n}-t_{n}+1$ is its being located up to $t_{n}$ and thus making the present tense belief 'My headache exists (now)' true up to $t_{n}$, and false at $t_{n}+1$ (and later). Similarly, a headache's beginning to exist at $t$ is nothing more than its being located at $t$ and not earlier, and thus making the present tense belief 'My headache exists (now)' true at $t$ and false earlier. ${ }^{12}$

The issue is not whether A- or B-theories succeed in resolving a dilemma concerning time relations, although I clearly prefer the latter. The point I am emphasizing is that there is a fundamental difference between A-passage and B-succession since they offer different accounts of the ontological categories needed to explain the relational aspect of time. The presentist appeals to (nonrelational) present-tensed facts and denies primitive temporal relations, whereas the B-theorist accepts primitive temporal relations and rejects all tensed properties and facts.

At the beginning of this paper I claimed that what Williams should have said, and to some extent has shown, is that there is only one true conception of time, namely, B-time. I want to conclude my essay by briefly explaining my rationale for that claim. Recall that there are basically two different ways in which A-time has been understood. Either the A-theory maintains that (1) succession is analyzable in terms of tensed facts and/or tensed properties, or that (2) in addition to a primitive, unanalyzable relation of succession, there are 
A-properties that temporal items acquire and shed. Whichever interpretation one adopts, Williams writings tend to support the B-theory. Let me explain.

In "A Bergsonian Response to McTaggart's Paradox" (1996b), Williams says:

Now clearly there is only one kind of time: A-time if the A-theorists are correct or B-time if the B-theorists are correct. So when we employ Bergsonian intuition, we are immersing ourselves in only one kind of time. But suppose we try to imagine ourselves being immersed in some different kind of time. We find that we cannot do so. Perhaps I should say, I cannot do so. I draw a blank. All I get is an intuition of the kind of time that actually exists. If I imagine that the A-theory is true and that I am intuiting A-time, I cannot also imagine what it would be like to intuit B-time. And if I imagine that the B-theory is true and that I am intuiting B-time, I cannot also imagine what it would be like to intuit Atime. I cannot, in short, imagine intuiting a different kind of passage (1-2).

Suppose Williams is correct, and we can immerse ourselves in only one kind of time. What follows from that? Clearly, it is invalid for Williams to argue that since he has no intuition of two kinds of time, the distinction between Aand B-time is spurious. Just because we cannot intuit time in both of these ways, it does not follow that there is no metaphysical distinction between the two theories any more than it follows that there is no metaphysical difference between the realist and the resemblance theories of the recurrence of qualities merely because we cannot intuit the difference between qualities as universals and qualities as particulars.

A more plausible argument is that since we experience time as involving primitive B-relations and not primitive A-properties, the B-theory is correct. Interestingly, this phenomenological argument is one that Williams himself has made. In an earlier account of our experience of time he has said that we only experience B-time. Thus Williams has claimed that "contrary to A-theorists, ... a correct account of our experience of time confirms the B-theory and not the A-theory. We do not experience the mind-independent A-properties that the A-theory says that events possess" ([1994a], 360). I take it that Williams would agree with his previous remarks concerning the phenomenology of Aproperties and B-relations even if he would disagree that there is a metaphysical difference between the two theories. Indeed, assuming that we should take the world as we experience it unless there are strong dialectical reasons to do otherwise, Williams should have said that the metaphysics of B-time is thereby the way the world is. More importantly, the fact, if it is a fact, that we only experience B-relations does not render the dispute between A- and B-time a pseudo problem.

Suppose we adopt the second interpretation of A-time and think of time as involving both temporal properties and temporal relations. For various reasons that he only hints at, Williams believes that the traditional A-theory "borders on the absurd" for he says that 
if A-time is thought of as being added to B-time, then it will be thought of as a mysterious kind of movement against the backdrop of B-time, somewhat analogous to the movement of things in space. It will seem to B-theorists to be both unneeded, because there already is transition, namely, B-time, and contradictory, because it is the movement of time in time.

Now, if Williams is right in his criticism of the traditional A-theory, and I think he is, then what follows is that we are left with only one kind of time, namely, B-time. For if we take away the moving now from the second interpretation of A-time, then we are left with primitive temporal relations. Furthermore, Williams has pointed out important misinterpretations that have motivated A-theorists' rejection of the B-theory. Once these misconstruals are unmasked, the dialectical difficulties with the A-theory spelled out, and the phenomenology of time understood to be relational, the B-theory can be judged to be adequate to the reality, and our experience, of time.

But is Williams' B-theory bias justified? Is there something unbelievable about A-time containing both the time relations of B-time and the modalities of past, present, and future? It is not my intention to pursue that question in this paper since I have done so extensively elsewhere (Oaklander and Smith [1994], Oaklander [1994, 1996]). Nevertheless, I think I have demonstrated that there are important metaphysical differences between alternative versions of the A-theory and the B-theory, and have given some reason to think that Williams is implicitly (and in my view correctly) sympathetic with the Btheory. That some distinction between the two theories really exists is further suggested by the fact that the differences I have explained seem to connect with other important issues in metaphysics. For example, William Lane Craig (1996b) has argued that the A-theory implies "the reality of the transcendental ego, or self. Just as there is an objective present, so there must also be a substantival self" (261; emphasis added). Furthermore, William Carter, Scott Hestevold (1994), and Trenton Merricks (1995) have argued that the tensed theory implies an endurance (or continuant) view of identity through time and the tenseless theory implies a perdurance (or temporal parts) view (cf. Le Poidevin, 1992). Moreover, if the B-theory is correct and there are no tensed properties, then the tenser-detenser debate has clear implications for those working in the philosophy of language who argue that the semantics of temporal indexicals imply that there are A-properties. If the two theories do have these and other implications, then philosophical progress on fundamental topics in metaphysics and the philosophy of language (as well as other areas) can be made by continuing the debate between A- and B-time. ${ }^{13}$ Whether the A- and B-theories do in fact have all of the different implications that they appear to have is a question that lies beyond the scope of this paper. Be that as it may, I think I have shown, in answer to the question of this paper, that yes, there are indeed metaphysical differences between A- and B-time. 


\section{ENDNOTES}

Earlier versions of this paper were presented at the Philosophy of Time Society, at the Central Division meetings of the American Philosophical Association, in Chicago on April 26, 1996, and at a conference on "Time, Tense and Reference" at Santa Barbara City College on April 12, 1997. I wish to thank Laird Addis for his useful comments on that paper. I have also benefited from the comments of Quentin Smith and Hugh Mellor.

${ }^{1}$ For recent attempts to defend the B-theory, see Le Poidevin (1992), Mellor (1998a, b), Oaklander (1984 and 1998), Smart (1981), and the essays by MacBeath, Mellor, Oaklander, and Williams in Oaklander and Smith (1994).

${ }^{2}$ For a defense of this interpretation of McTaggart's positive conception of time, see Oaklander ([1984], chap. 2, and [1996]). For a criticism of it, and an alternative interpretation see Farmer (1990).

${ }^{3}$ For objections to the B-theorist position about the relation between ordinary language and thought, and metaphysical analysis, see Craig (1996a, 1996b) and Smith (1993).

${ }^{4}$ This quote comes from Hasker (1989), 127-8. Unfortunately, some of the things that Williams says about the B-theory are themselves ambiguous and may lead to just those misinterpretations of B-time that Williams sought to avoid. For example, he says that "Btime does not just consist of permanent facts; [i.e., facts expressed by B-statements such as 'Kirsten and Lee marry (tenseless) on 27 February 1993'] it consists also of transition between the events that make up the facts, and this transition makes B-time 'dynamic' (379). The notion of "permanent" facts suggests that the fact expressed by "Kirsten and Lee marry (tenseless) on 27 February 1993" always exists. Of course, B-facts are not permanent in that sense since they do not exist at everytime. As I have argued elsewhere (1984), B-facts do not exist in time at all, although all tokens of a B-sentence type have a permanent truth-value in that they are always true or always false.

${ }^{5}$ This passage is from a draft of Smith (1998), and in private correspondence Smith expressed his full endorsement of it.

${ }^{6}$ For a fuller treatment of the problem of change, see C. D. Broad (1959), chap. 2; Le Poidevin (1992), 13-23; Smith and Oaklander (1995), 57-65; and Oaklander (1996, 1998a).

${ }^{7}$ For a penetrating discussion of this reductionist gambit, see Wilson (1995). The classic critique of the monadistic account is found in Russell (1938, chap. 26).

${ }^{8}$ McTaggart's definition of "earlier than" in terms of A properties is: "The term P is earlier than the term Q, if it is ever past while $Q$ is present, or present while $Q$ is future" (McTaggart, [1959], 271). For a critical discussion of McTaggart's definition, see Gale ([1968], 90-1).

${ }^{9}$ For a criticism of Bigelow's response to McTaggart, see Oaklander (1994b). It should be noted that Bigelow has changed his views on time and now adopts a variant of presentism (1996).

${ }^{10}$ Some philosophers maintain that intentionality is an "abnormal" relation between a mental act and its object since it can connect an existent with what does not exist. See, for example, Grossmann (1983).

${ }^{11}$ See Zimmerman (1996). 
${ }^{12}$ To this it might be objected that since the knowledge of my headache ceasing to exist requires that the tensed beliefs "My headache exists (now)" and "My headache did exist" are both true (at different times), there must be tensed facts to account for their truth. The inference, however, is fallacious. For if a belief or judgment is indexical, as it is if is tensed, then its truth conditions are token-reflexive. So all it takes to make a token of the tensed belief "My headache exists (now)" true is that the headache occurs simultaneously with the belief. And all it takes to make a token of the tensed belief, "My headache did exist" true is that the headache ended before I had the belief (or that the belief is held after the end of the headache).

${ }^{13}$ For a discussion of ways in which the debate connects with issues in the philosophy of religion, the philosophy of logic, the philosophy of language, and the philosophy of science, see, Oaklander and Smith (1994), 1-14. The connection between time and identity is explored in Oaklander (1992), and time and freedom in Oaklander (1998b).

\section{BIBLIOGRAPHY}

Bigelow, J. 1991. "Worlds Enough for Time.” Nous 45: 1-20.

- 1996. "Presentism and Properties." Metaphysics. Philosophical Perspectives, Vol. 10, edited by J. Tomberlin, 35-52. Cambridge, MA: Blackwell.

Bradley, F. H. 1987. Appearance and Reality. 2d ed. Oxford: Oxford University Press.

- Broad, C. D. 1921. “Time.” In Encyclopedia of Religion and Ethics, edited by J. Hastings, 334-45. New York: Scribner's Sons.

- 1923. Scientific Thought. London: Routledge and Kegan Paul.

. 1938. Examination of McTaggart's Philosophy, 2 vols. Cambridge: Cambridge University Press.

Carter, W., and S. Hestevold. 1994. "On Temporal Passage and Temporal Persistence." American Philosophical Quarterly 31, 2: 269-83.

Craig, W. L. 1996a. “The B-Theory's Tu Quoque Argument.” Synthese 107: 249-69.

\section{$5-26$.}

Farmer, D. J. 1990. Being in Time. New York: University Press of America.

Gale, R. 1968. The Language of Time. New York: Humanities Press.

Grünbaum, A. 1963. Philosophical Problems of Space and Time. 1st ed., New York: Alfred Knopf.

Hasker, W. 1989. God, Time and Knowledge. Ithaca: Cornell University Press.

Le Poidevin, R. 1992. Change, Cause and Contradiction: A Defense of the Tenseless Theory of Time. New York: St. Martin's Press.

Lowe, E. J. 1998. “Tense and Persistence." In Questions of Time and Tense, ed. Robin Le Poidevin, 43-59. Oxford: Clarendon Press.

Markosian, N. 1993. "How Fast Does Time Pass?" Philosophy and Phenomenological Research 53, 4: 829-44. 
McTaggart, J. E. M. 1908. "The Unreality of Time." Mind 17: 457-74.

. 1927. The Nature of Existence, edited by C. D. Broad. Vol. 2. Cambridge: Cambridge University Press.

Mellor, D. H. 1998a. Real Time II. New York: Routledge.

. 1998b. "Transcendental Tense I." Aristotelian Society Supplement 72.

Merricks, T. 1995. "On the Incompatibility of Enduring and Perduring Entities." Mind 104: 415, 523-31.

Oaklander, L. N. 1984. Temporal Relations and Temporal Becoming. Lanham, MD: University Press of America.

— 1992.“Temporal Passage and Temporal Parts." Nous 26, 1: 79-84.

1994. "Bigelow, Possible Worlds and the Passage of Time." Analysis 54, 4: 244-8.

. 1996. "McTaggart's Paradox and Smith's Tensed Theory of Time." Synthese 2: 205-21.

- 1998a. "The Problem of Time and Change." Stoa, An International Undergraduate Journal in Philosophy 1: 85-109.

. 1998b. "Freedom and the New Theory of Time." In Questions of Time and Tense, edited by R. Le Poidevin, 184-205. Oxford: Clarendon Press. . 1999. "Review of Michael Tooley's Time, Tense and Causation." Mind.

Oaklander, L. N., and Q. Smith, eds. 1994. The New Theory of Time. New Haven: Yale University Press.

Prior, A. N. 1968. Time and Tense. Oxford: Oxford University Press.

Russell, B. 1938. The Principles of Mathematics, 2d ed. New York: W. W.

Norton \& Co.

. 1915. "On the Experience of Time." Monist 24: 212-33.

Schlesinger, G. (1980). Aspects of Time. Indianapolis: Hackett Publishing Co.

_ 1994a. "Temporal Becoming." In Oaklander and Smith, 214-20.

- 1994b. "The Stream of Time." In Oaklander and Smith, 257-87.

Shorter, J. M. 1984. "The Reality of Time." Philosophia 14: 321-39.

Smart, J. J. C. 1981. "The Reality of the Future.” Philosophia 10: 141-50.

Smith, Q. 1993. Language and Time. New York: Oxford University Press. 1998. "Absolute Simultaneity and the Infinity of Time." In Questions of Time and Tense, edited by R. Le Poidevin, 135-83. Oxford: Clarendon Press.

Smith, Q., and L. N. Oaklander. 1995. Time, Change and Freedom. New York and London: Routledge.

Tooley, M. 1997. Time, Tense and Causation. Oxford: Oxford University Press.

Williams, C. 1994. “The Phenomenology of B-Time.” In Smith and Oaklander, $360-72$.

- 1996a. "The Metaphysics of A- and B-Time." The Philosophical Quarterly 46: 371-81. 1996b. "A Bergsonian Response to McTaggart's Paradox," read at the Philosophy of Time Society meetings in Chicago, Illinois. 
Williams, D. C. 1951. "The Myth of Passage." The Journal of Philosophy 48: 457-72.

Wilson, F. 1995. "Burgerskijck, Bradley, Russell, Bergmann: Four Philosophers on the Ontology of Relations." Modern Schoolman 74, 4: 283-310. Zeilicovici, D. 1994. "Temporal Becoming Minus the Moving Now." In Oaklander and Smith, 234-51.

Zimmerman, D. 1996. "Reply to Clifford Williams' 'The Metaphysics of Aand B-Time," read at the Philosophy of Time Society meetings in Chicago, Illinois. 